\section{B A Institute of \\ YK Business Administration \\ 六下 \\ Karachi \\ Leadership and Ideas for Tomorrow}

Business Review

Volume 13 Issue 1 January-June 2018

6-13-2018

\title{
Is poverty the cause of nonattendance in schools and prevalence of idleness in children? A regional analysis of Sind
}

\author{
Sarah Abdul Rahim \\ Institute of Business Administration, Karachi, Pakistan \\ Khadija Bari \\ Institute of Business Administration, Karachi, Pakistan
}

Follow this and additional works at: https://ir.iba.edu.pk/businessreview

\section{(c) (9)}

This work is licensed under a Creative Commons Attribution 4.0 International License.

\section{Recommended Citation}

Rahim, S. A., \& Bari, K. (2018). Is poverty the cause of nonattendance in schools and prevalence of idleness in children? A regional analysis of Sind. Business Review, 13(1), 37-51. Retrieved from https://doi.org/10.54784/1990-6587.1036 


\title{
Is poverty the cause of nonattendance in schools and prevalence of idleness in children? A regional analysis of Sind
}

\author{
Sarah Abdul Rahim . Khadija Bari
}

\begin{abstract}
This paper investigates the extent to which poverty determines the activities of children in the province of Sind. A structured demand model is estimated using multinomial logit regression, whereby the effect of the variables poverty, mother autonomy and gender equality are measured on schooling, student labour, child labour and idleness. The results reveal that greater poverty levels negatively impact parents' decision regarding child schooling. Furthermore, higher educational gender equity and mother empowerment is positively associated with child schooling.
\end{abstract}

Keywords Schooling · Student labour · Idleness · Gender equality · Mother autonomy.

\section{Introduction}

Poverty reduction is the foremost objective of the sustainable development goals of Pakistan. It is of dire importance to address this issue given the critical situation of the country in this regard. $44 \%$ of the households in Pakistan are residing below the poverty line. The poorest and most deprived living conditions exist in Thatta, Sanghar and Hyderabad (all in Sind) (Padda and Hameed 2018).

Literature regarding the determinants of child schooling and child labour in the context of developing countries, indicates that poverty is amongst the key factors that explains parent's inability to send their child to school (Azid and Ejaz Ali Khan 2010; Duraisamy et al 2000; Haile and Haile 2012). Consequently, empirical studies on the subject infer a positive relationship between poverty and child labour as well as idleness (Haroon, 2014). Children are forced to share the economic responsibilities as the basic requirements of the household cannot

Sarah Abdul Rahim

Institute of Business Administration, University Road, Karachi-Pakistan

E-mail: sarahim@iba.edu.pk

Khadija Bari

Institute of Business Administration, University Road, Karachi-Pakistan 
be met without doing so (Zafar et al 2014). Therefore they are made to earn a livelihood at the cost of their education Kazmi (2015).

Decisions concerning child schooling, child labour and idleness are visibly associated with a household's economic status. This status may be determined either by the wealth endowments of a household or a lack there of. Data sourced from different sources (Multiple Indicator Cluster Survey for example) displays only the possession (Yes/No) of household assets, a metric that may serve as a proxy for wealth levels. It would, however, be inappropriate to evaluate wealth levels without accounting for the market value of assets, the number of assets and the date of purchase of the said assets (Acemoglu and Robinson 2010). Considering the aforementioned potential for complexities, evaluating household economic statuses on the basis of poverty and deprivations instead, appears to be a more desirable option.

Besides poverty, related studies have also pointed towards parental education and socio-economic conditions being significant determinants of a child not being schooled, doing labour or remaining idle. These studies have accounted for variables such as child characteristics, household demography, age and occupation of the father, spatial variations with respect to culture and the level of regional development.

An essential precursor of regional development is gender equality; it is central to fairness and inclusive societal development. The gender development index (a measure of gender equality) captures the disparities between men and women in education, health, employment and income; a higher index indicates more equitable gender relations. A higher index implies greater autonomy of the mother in decision making, leading to improved child welfare especially in terms of schooling, working or choosing to remain idle (Kambhampati 2009).

The following paper contributes to existing literature in three unique aspects. First, the paper utilises a multi-dimensional tactic and attempts to evaluate poverty using multiple metrics. This incorporates non-income, socio-economic deprivations in order to establish the household poverty position, with the aid of the Multidimensional Poverty Index (MPI) ${ }^{1}$ Former literature primarily relied on income levels, wealth index quintile or the poverty line to represent poverty status and how it impacted a child's activities (Ray and Basu 2002; Fatima 2017).

Second, an effort has been made to establish a relationship between female autonomy, and child school attendance, work participation and idleness. Much of the existing literature regarding female autonomy is majorly concerned with fertility, infant mortality, child health and house-hold expenditure styles. The author is aware of only a limited number of papers in this specific area of research, none of which are relevant to Pakistan (Sind) (Afridi 2010; Ray and Basu 2002; Kambhampati 2009; Lancaster et al 2006).

Third, the study not only examines the impact of individual autonomy characteristics, it also accounts for the environment within which women live. A majority of the applied studies on female autonomy lean towards autonomy within the household (Kravdal (2004) is an exception to this). When considering Pak-

1 A brief note on the methodology employed is available in the appendix. 
istan in the context of female autonomy, the country ranks second last on the gender inequality index, which implies that female autonomy is almost nonexistent. Expanding the literature would not only prove interesting, but fruitful as well in this regard. Regional variances in gender equity assist in establishing the norms that many households find problematic to disregard (Kambhampati 2009).

\section{Literature review}

In the province of Punjab, child absenteeism in schools is a direct consequence of poverty, as determined by Haroon (2014). Likewise, poverty is seen as the primary trigger prompting households to push their children into labour, as observed by Koissy (2012) in his study on Sub-Saharan rural regions. The core motivation behind this decision is the added income brought forth by children engaging in labour as opposed to schooling.

Similarly, Kazmi (2015) identified parental education and poverty, in the Sahiwal district of Punjab, as the two main drivers of child labour. Paradoxically, wealthy, land-owning households in such rural vicinities are just as motivated to have their children avoid schooling. They prefer having their children work on their farmlands, so as to compensate for land, labour and credit imperfections (Koissy 2012).

Hou (2010) deemed that household wealth is a critical factor in determining the activities that dominate a child's life. A study on Nepalese children moves a step ahead to show that higher wealth not only reduced child labour, it also protected children from severe physical and emotional abuse (Atteraya et al 2018). However, it is inadequate to consider wealth as the sole determinant of child enrolment in schools, particularly in the context of rural, female children.

Expanding upon the discussion on wealth, Bacolod and Ranjan (2008) concluded that the decision to send a child to school or engage in labour is influenced by a combination of the household's wealth status and the child's abilities (in Philippines). In addition to this, the same study also argued that households that owned businesses or had working mothers, exhibited a significantly higher probability of children working and acquiring an education simultaneously (Bacolod and Ranjan 2008).

Similar results were narrated by Eric and Schady (2009) in their analysis of poor Ecuadorian households. Child labour was only prevalent in households that had income levels below the subsistence level. Given an income level above the subsistence level, parents disregarded the option of child labour, with the potential earnings from child labour having no merit in this decision-making process.

Investigations of Del Carpio (2008) into the effects of Conditional Cash Transfers contradicted these findings. Their evaluation of Nicaraguan households highlighted that increments in household income levels did not translate into a consistent decline in child labour. Similarly Krauss (2013) raises a contention to Eric and Schady (2009), suggesting that whilst there is a seemingly definitive correlation between poverty and the incidence of child labour, evi-

Business Review: (2018) 13(1):37-51 
dence from agrarian economies such as Ghana refute the aforementioned claim.

Duraisamy et al (2000) noted that maternal education is a compelling influencer in improving school enrolment rates and lowering child labour levels. In situations where the mother or the household head lacks education, there is a greater chance that the family will push the children into the labor market (Awan et al 2011).

Similarly, Kambhampati (2009) analysis of the Indian population revealed that a mother's education level and her contributions to household expenditures serve as crucial determinants of the probability of a child receiving schooling, and/or engaging in labour. The impact of these determinants was particularly dependant on the prevalence of gender equity; lower levels of gender equity may entirely offset any autonomy a mother would otherwise have.

Research of Pakistani and Nicaraguan children by Rosati and Rossi (2003) highlighted that children belonging to large families, or high-income households enjoyed fewer working hours. Additionally, they pointed out that in Pakistan, female children had a lower likelihood of receiving schooling than their male counterparts. Analogous to this Ray et al (2001), in his analysis of Pakistan's child labour found that there is an inverse relationship between schooling received and hours of work, whilst a positive relationship exists between poverty and hours of work.

\section{Theoretical framework}

This study utilizes the theoretical framework proposed by Edmonds (2007), albeit with certain modifications. Within this framework, a child's time is allocated to four distinct activities: education $E$, leisure and play $P$, work outside of the household $M$, and work inside of the household $H$.

The household itself has been defined over two time periods and constitutes one parent and one child (this is assumed for simplicity). Parents, who assume the role of decision makers for the household, have the function of utility $U\left(V_{0}, V_{1}\right): V_{0}$ being the current living status of their children, and $V_{1}$ being the potential living status, in the future (period 1 ).

Edmonds (2007) considers four separate child activities; however, it is quite possible that a child combines these four activities. For example, a child may attend school and work, or the child may attend school as well as take care of his siblings (domestic chores). This paper, thus, divides the activities of a child into four categories, while taking into consideration that a child may undertake two activities simultaneously: schooling (child goes to school only), student labor (child works and attends school), child labor (child works only) and idleness (child neither goes to school nor works).

This model implies that the parents would derive a higher marginal utility if the child works than in the case of sending the child to school or letting him remain idle at home.

$$
M U_{\text {childlabour }} \geq M U_{\text {studentlabor }} \geq M U_{\text {schooling }} \geq M U_{\text {idle }}
$$

The household's decision of their child's activities depends on the marginal utility yielded by each activity and is at least as large as the utility being derived 
from the forgone alternative.

The aforementioned four activities, thus guide the remainder of this theoretical and empirical analysis. Marginal utility of work serves as the input of the child to the current living standard of the household through the wage that he is earning in the market (Hou 2010). Therefore, marginal utility, being derived from various options, is a composition of a vector of different factors. The factors guiding each activity can, therefore, be represented in the following reduced form equation:

$$
y=f(\text { householdpoverty, regionalgenderequity, motherempowerment) }
$$

Household poverty is a key determinant of the supply of child labour. It impacts the valuation of a child's time within the household as well as in the labour market; a poor household's marginal utility of sending a child to work will be higher than the marginal utility of sending him to school.

Similarly, a region where there is more gender equity the marginal utility of sending a child to school will be higher than making the child work or letting him be idle. Women in more gender equitable regions are more educated and more likely to work therefore they choose the same for their children. Furthermore, if a woman is more autonomous in her decision making (based on her schooling and earnings) then the marginal utility of sending her child to school will be higher than making the child work.

\section{Data}

\subsection{Descriptive analysis}

The study uses the most recently published Multiple Indicator Cluster Survey (MICS) data for the province of Sind. The survey contains data on 29,885 children between ages 5-14.

The 5-14-year age group is deemed most suitable for documentation procedures for the status of children in Sind, with respect to schooling, laboring and idleness. For policy analysis purposes estimation of school enrollment rates is determined using age groups 5-9 years and 10-14 years for primary and secondary level schooling, respectively.

Table 1 shows the distribution of children's activities in the province of Sind and also highlights the gender and regional differences. According to the estimates derived from the MICS-2014, about 52 percent children in the 5-14 age cohort are currently enrolled, 9 percent attend school as well as work, 11 percent are reported to be in the labor market and a sizable 28 percent are invisible or idle.

46 percent of the girls attend school as compared to 52 percent of the boys. 12 percent of the girls work in the labor market whereas 36 percent of the girls are idle. On the contrary 10 percent of the boys work whereas 26 percent are idle.

The percentage of children attending school in urban areas is almost double than those attending school in rural areas, however there are 13 percent more

Business Review: (2018) 13(1):37-51 
idle children in rural areas than in urban areas. In urban areas 20 percent of the boys and 24 percent of the girls whereas in rural areas 30 percent of the boys and 47 percent of the girls are idle.

Table 1: Children's activities: gender and regional scenario (percentage of children in 5-14 age cohort)

\begin{tabular}{|c|c|c|c|c|c|c|}
\hline & & & School only & School \& work & Work only & Idle \\
\hline Sindh & & & 52.44 & 9.2 & 10.14 & 28.22 \\
\hline \multirow{2}{*}{ Gender } & & Girls & 45.6 & 6.34 & 11.7 & 36.35 \\
\hline & & Boys & 52.69 & 11.32 & 10.43 & 25.56 \\
\hline \multirow{6}{*}{ Area } & & Urban & 68 & 6 & 5 & 21 \\
\hline & & Rural & 37.52 & 12.49 & 15.17 & 34.82 \\
\hline & \multirow{2}{*}{ Rural } & Girls & 27.88 & 7.95 & 17.33 & 46.83 \\
\hline & & Boys & 40.11 & 14.83 & 14.66 & 30.41 \\
\hline & \multirow{2}{*}{ Urban } & Girls & 66.25 & 4.46 & 5.15 & 24.14 \\
\hline & & Boys & 68.08 & 7.03 & 5.26 & 19.64 \\
\hline
\end{tabular}

\subsection{Household poverty and child status}

Data from Sind Multiple Indicators Clusters Survey (MICS, 2014) is subjected to the OPHI methodology, ${ }^{2}$ to estimate the household poverty scores against a particular deprivation indicator. In Sind 43 percent of the people are MPI poor $^{3}$ as depicted in table 2 . These poor people are deprived in 51 per cent of the weighted indicators.

10 percent of the population is vulnerable to poverty where as 24 percent lives in severe poverty as depicted by table 2 . The estimated value of MPI is 22 (it is a product of headcount and intensity). There are distinct differences between the poverty levels in rural and urban areas as indicated in table 2; rural areas being poorer. As per table 3 only 21 percent of the children belonging

Table 2: Dimensions of multidimensional poverty

\begin{tabular}{lccccc}
\hline & MPI & Headcount & Intensity & Vulnerable & Severity \\
\hline Overall & 22.23 & 43.34 & 51.3 & 10.43 & 23.63 \\
Rural & 34.81 & 65.75 & 52.94 & 13.15 & 38.91 \\
Urban & 9.99 & 21.51 & 46.43 & 7.78 & 8.75 \\
\hline
\end{tabular}

to the high poverty score attend school, 22 percent work only and a sizeable 50 percent are idle, whereas, in low poverty scores 79 percent attend school, 2 percent work and only 11 percent are idle.

Figure 1 depicts a typical profile of a poor child in Sind; the child will

2 A detailed note is provided in the appendix.

3 This means that they are in acute poverty. They are deprived at least either a) in all the indicators of a single dimension or b) in a combination across dimensions such as being in a household with a malnourished person, no clean water, a dirt floor and un-improved sanitation. 
Is poverty the cause of nonattendance...

Table 3: Distribution of children's activities according to household poverty status(percentage of children in 5-14 age cohort)

\begin{tabular}{clcccc}
\hline & & School only & School \& work & Work only & Idle \\
\hline \multirow{3}{*}{ Overall } & Low poverty score & 78.81 & 8.75 & 1.66 & 10.78 \\
& Medium poverty score & 44.58 & 10.88 & 10.06 & 34.48 \\
& High poverty score & 20.57 & 7.45 & 22.34 & 49.64 \\
\hline
\end{tabular}

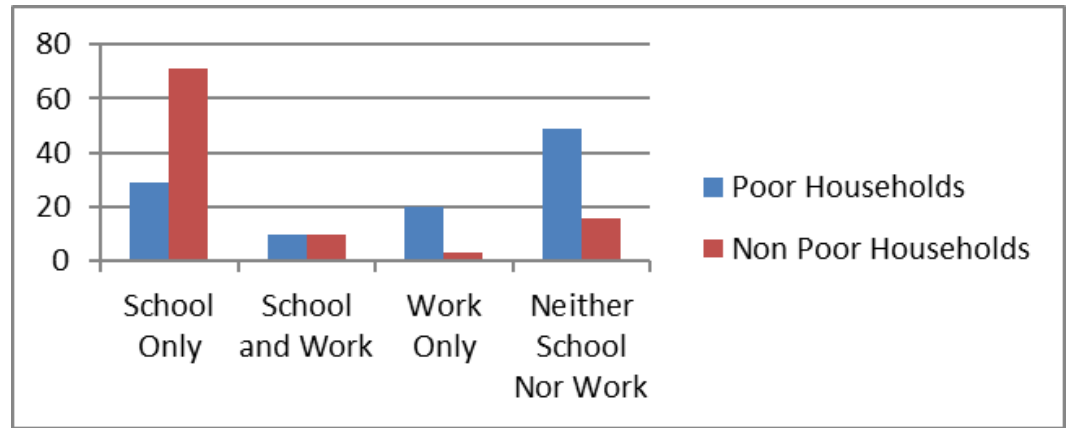

Fig 1: Activities of a poor child in Sind

either be working or idle. Only 29 percent attend school whereas 9 percent attend school as well as work.

\subsection{Mother autonomy}

In addition to the mother's own level of education, her education relative to the father, is representative of the mother's autonomy within a household. Figure 2 clearly depicts the positive impact on schooling in cases where the mother is more educated than the father. However, a similar impact is not seen in the case of child work and idleness. This may be due to some other factors that are not controlled for in this research and therefore an econometric analysis is deemed necessary. For calculating gender equity ${ }^{4}$ households are arranged

Table 4: Children's activities according to extent of gender equity (percentage of children in 5-14 age cohort)

\begin{tabular}{lcccc}
\hline & School only & School \& work & Work only & Idle \\
\hline Low Gender Equity & 29.82 & 10.62 & 18.21 & 41.35 \\
Medium Gender Equity & 55.86 & 9.04 & 8.03 & 27.07 \\
High Gender Equity & 71.38 & 7.96 & 4.25 & 16.41 \\
\hline
\end{tabular}

in three percentile groups (33 percent each) on the basis of the magnitude of the gender equity index at the level of cluster (PSU). This establishes a link between educational environment in the adjoining area with respect to gender equity and the decision regarding childrens schooling or laboring. According to

${ }^{4}$ Details on how the index is developed is given in the methodology section.

Business Review: (2018) 13(1):37-51 


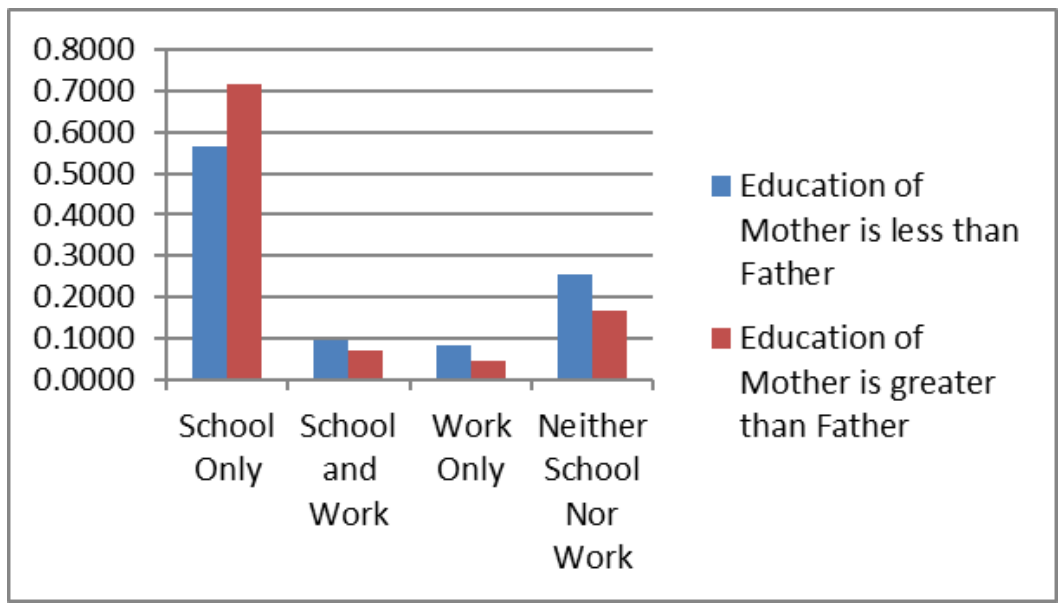

Fig 2: Impact on schooling of mother's education

table 4, 71 percent children are attending school in areas of high gender equity whereas only 30 percent are attending school in low equity regions. Similarly, difference in the estimates of child idleness is more than two times higher (41 versus 16) in areas of low gender equity.

\section{Methodology}

The paper mainly aims to test three hypotheses:

Hypothesis 1: Poverty increases labour and idleness and decreases schooling Hypothesis 2: Mothers with greater autonomy will increase child's welfare (increase child schooling, decrease child work and idleness)

Hypothesis 3: Gender equity conditions play an important role in determining whether a child attends school, works or remains idle

To test these hypotheses, the study approximates a structured demand model of a household's decision towards a child's well-being. This helps identify and further evaluate which factors mostly contribute towards the decisionmaking process that determine a child's move towards schooling or working or being idle. The primary focus of this research lies on essential determinants, namely household poverty levels, a mother's authority and power in household decision-making and gender equity.

\subsection{Empirical estimation}

To estimate the net impact of poverty, mother autonomy and gender equity we use the multinomial logit model. The dependent variable of the study child activity, denoted by $j$, is a categorical variable and can take any of the following four mutually exclusive values: $j=0$, if the child goes to school only 
$j=1$, if child works and attends school

$j=2$, if the child works only

$j=3$, if the child neither goes to school nor works

The main explanatory variables of the study are poverty, gender equity and mother autonomy. Calculation of the poverty status is performed using a multi-dimensional approach that accounts for non-income socio-economic deprivations. A Multidimensional Poverty Index (MPI) has been produced by

Table 5: Dependent variables

\begin{tabular}{|c|c|}
\hline \multicolumn{2}{|l|}{ Parents characteristics } \\
\hline Mother's education & $\begin{array}{l}\text { Dummy variable equal to } 0 \text { if mother has had no education, } 1 \text { if the } \\
\text { mother has completed primary education, } 2 \text { if the mother has com- } \\
\text { pleted middle secondary education, } 3 \text { if the mother has completed } \\
\text { secondary education, } 4 \text { if the mother has completed higher secondary } \\
\text { education and } 5 \text { if she has completed higher education }\end{array}$ \\
\hline Father's education & $\begin{array}{l}\text { Dummy variable equal to } 0 \text { if father has had no education, } 1 \text { if the } \\
\text { father has completed primary education, } 2 \text { if the father has completed } \\
\text { middle secondary education, } 3 \text { if the father has completed secondary } \\
\text { education, } 4 \text { if the father has completed higher secondary education } \\
\text { and } 5 \text { if he has completed higher education }\end{array}$ \\
\hline \multicolumn{2}{|l|}{ Household characteristics } \\
\hline Poverty score & $\begin{array}{l}\text { Dummy variable equal to } 1 \text { if house has a low poverty score, } 2 \text { if the } \\
\text { house has medium poverty score and } 3 \text { if house has high poverty score }\end{array}$ \\
\hline Gender of household head & Dummy variable equal to 1 if male and 2 if female \\
\hline Family size & Total number of household members \\
\hline Mother autonomy & $\begin{array}{l}\text { Dummy variable equal to } 0 \text { if mother and father have equal education } \\
\text { and } 1 \text { if father has higher education as compared to mother }\end{array}$ \\
\hline \multicolumn{2}{|l|}{ Child characteristics } \\
\hline Gender of child & Dummy variable equal to 0 if male and 1 if female \\
\hline Age of child & Completed years of age of the child \\
\hline \multicolumn{2}{|l|}{ Community characteristics } \\
\hline Area & Dummy variable equal to 1 if urban and 2 if rural \\
\hline Gender Equity Index Score & $\begin{array}{l}\text { Dummy variable equal to } 1 \text { if low gender equity, } 2 \text { if medium gender } \\
\text { equity and } 3 \text { if high gender equity }\end{array}$ \\
\hline Division & $\begin{array}{l}\text { Dummy variable equal to } 1 \text { if it is Larkana Division, } 2 \text { if Sukkur Di- } \\
\text { vision, } 3 \text { if Hyderabad Division, } 4 \text { if Mirpurkhas Division and } 5 \text { if } \\
\text { Karachi Division. }\end{array}$ \\
\hline
\end{tabular}

the Oxford Poverty and Human Development Initiative (OPHI), which accounts for 10 non-income deprivation indicators for more than 100 countries. The outcomes of this exercise have been published since 2010, by the UNDP Human Development Report. The published results have been categorized according to country rankings and extent of multidimensional poverty. The OPHI methodology is, therefore, applied to the Sind Multiple Indicators Clusters Survey (MICS, 2014) in order to approximate the rankings of household poverty with respect to the specified deprivation indicators.

Similarly, utilizing the same data, a gender-related education index is also developed that allows for an evaluation of the correlation between child activities concerned with schooling and working, and contiguous educational environment in terms of gender equity. The index abides by the principle of equally dis-

Business Review: (2018) 13(1):37-51 
tributed indexes, as practiced by the UNDP Gender-related Development Index (GDI). The index incorporates male and female education indexes in a method which penalizes the variations between achievements of men and women.

To calculate a collective index for education, indices of male and female clusters were produced, by allocating equal weightage to mean years of schooling and expected years of schooling. The individual indexes were then amalgamated with the following formula:

$$
\begin{aligned}
& \left(\text { femalepoulationshare } \times \text { femalepopulationinde } x^{-1}\right. \\
& \left.\qquad+ \text { malepopulationshare } \times \text { maleeducationinde } x^{-1}\right)^{-1}
\end{aligned}
$$

The value of the index varies between 0 and 1; 0 being no gender equity and 1 being perfect gender equity. Socioeconomic variables as controls have also been introduced in the model. The impact of these variables on child activities has been widely reported in literature. These are listed in table 5 .

Marginal probabilities are calculated for the four categories of the dependent variables. The probability derivatives are calculated at the mean of the explanatory variable and identify the change in dependent variable due to a one-unit change in the dependent variable, holding rest of the variables constant. $P_{j}$ are probabilities attached with the four categories of the dependent variable:

$P_{0}=$ probability of study (not working)

$P_{1}=$ probability of combining study and work

$P_{2}=$ probability of work (not attending school)

$P_{3}=$ probability of neither work nor study

Under the model used, these probabilities are estimated using the equation:

$$
P\left(j / x_{j}\right)=P_{j}=1 / 1+\exp \left(x_{j}^{\prime} \beta_{1}\right)+\exp \left(x_{j}^{\prime} \beta_{2}\right)+\exp \left(x_{j}^{\prime} \beta_{3}\right)
$$

The category study is taken as the reference category, so $\beta_{0}=0$ and $\beta_{1}, \beta_{2}$ and $\beta_{3}$ are the covariate effects of the response categories: study and work, work only and idleness, respectively.

\section{Results and discussion}

\subsection{Descriptive Statistics}

Table 6 presents the descriptive features of the sample considered for this study. Mothers, on average, have acquired middle secondary education whereas fathers have completed secondary education. The households sampled primarily have a medium poverty score and males as their family heads. Family size on average is eight people. Predominantly, in a particular household, fathers have secured higher education than mothers. There are approximately fifty percent of male and female children sampled. Mean age of children included in the sample is nine years. The households, on average, fall under medium gender equity.

\subsection{Regression Results}

Table 7 presents the results from the multinomial logit model. 
Is poverty the cause of nonattendance...

Table 6: Summary statistics of the dependent variables in the equation

\begin{tabular}{lcc}
\hline & \multicolumn{2}{c}{ Sind } \\
Variable & Mean & Std Dev \\
\hline Parental characteristics & & \\
Mother's education & 1.85 & 1.43 \\
Father's education & 2.8 & 1.8 \\
Household characteristics & & \\
Poverty score & 1.9 & 0.83 \\
Gender of household head & 1.04 & 0.2 \\
Family size & 8.2 & 3.94 \\
Mother autonomy & 0.15 & 0.36 \\
Child characteristics & & \\
Gender & 0.52 & 0.5 \\
Age & 9.33 & 2.89 \\
Regional characteristics & & \\
Area & 1.52 & 0.5 \\
Gender Equity Index score & 2.01 & 0.82 \\
Division & 3.01 & 1.34 \\
\hline
\end{tabular}

\subsubsection{Hypothesis 1: Poverty increases labour and idleness and decreases schooling}

There is a 25 percent probability that a child belonging to the poorest household will not attend school and be idle (a probability of 34 percent) or work (a probability of 2.4 percent) as presented in table 7 . The result establishes firm evidence that there is a strong interconnection between poverty and idle children. In fact, the magnitude of the estimated coefficient as well as the marginal effect, confirms that it is the most important determinant of child schooling (or a child working or remaining idle). A poor household would be monetarily constrained and therefore the decision to send its child to school would be adversely impacted.

Additionally, the child may also be required to work in order to generate some additional income for the family. Improvement in economic status of a household can dramatically reduce child work as well as idleness. This result is consistent with the previous literature; Haroon (2014) reports similar results for Punjab and Grigoli and Sbrana (2013) for Bolivia (Grigoli \& Sbrana, 2013).

6.2.2 Hypothesis 2: Mothers with greater autonomy will increase child's welfare (increase child schooling, decrease child work and idleness)

Higher levels of mother autonomy decrease idleness by 7 percent and child work by 0.4 percent (increase schooling by six percent) for our sample. However, an important thing to note here is that, although these results are in line with literature Kambhampati (2009), Haroon (2014), they are not significant. This might be because we have only considered the educational aspect for judging the degree of woman autonomy as there was no other data on female labour force participation or income contribution in the data set used (MICS 2014). It is also clearly reported in literature Kambhampati (2009) that mother autonomy measured only in terms of education yields statistically insignificant results.

Business Review: (2018) 13(1):37-51 
Table 7: Marginal effect of variables on child activities in Sind

\begin{tabular}{|c|c|c|c|c|}
\hline Variables & School only & School \& work & Work only & Idle \\
\hline \multicolumn{5}{|l|}{ Mother's education } \\
\hline Primary & $\begin{array}{c}9.26^{* * *} \\
(0.03)\end{array}$ & $\begin{array}{l}-0.34 \\
(0.01)\end{array}$ & $\begin{array}{c}-0.81^{* *} \\
(0)\end{array}$ & $\begin{array}{c}-8.11^{* * *} \\
(0.02)\end{array}$ \\
\hline Middle & $\begin{array}{c}12.80^{* * * *} \\
(0.04)\end{array}$ & $\begin{array}{c}-4.82^{*} \\
(0.03)\end{array}$ & $\begin{array}{c}-1.82^{* *} \\
(0.01)\end{array}$ & $\begin{array}{c}-6.14^{*} \\
(0.04)\end{array}$ \\
\hline Secondary & $\begin{array}{c}12.80^{* * *} * \\
(0.04)\end{array}$ & $\begin{array}{l}-2.28 \\
(0.02)\end{array}$ & $\begin{array}{l}-0.91 \\
(0.01)\end{array}$ & $\begin{array}{c}-9.63^{* *} \\
(0.04)\end{array}$ \\
\hline Higher-secondary & $\begin{array}{c}22.00^{* * * *} \\
(0.06)\end{array}$ & $\begin{array}{c}-2.3 \\
(0.03)\end{array}$ & $\begin{array}{c}-19.70^{* * *} \\
(0.03)\end{array}$ & $\begin{array}{c}0.08 \\
(0.05)\end{array}$ \\
\hline Higher & $\begin{array}{c}19.60^{* *} \\
(0.09)\end{array}$ & $\begin{array}{l}-3.02 \\
(0.05)\end{array}$ & $\begin{array}{c}-19.60 * * * \\
(0.03)\end{array}$ & $\begin{array}{c}3.05 \\
(0.09)\end{array}$ \\
\hline \multicolumn{5}{|l|}{ Father's education } \\
\hline Primary & $\begin{array}{c}10.30^{*} \\
(0.06)\end{array}$ & $\begin{array}{l}-1.12 \\
(0.03)\end{array}$ & $\begin{array}{l}-1.21 \\
(0.01)\end{array}$ & $\begin{array}{c}-8 \\
(0.05)\end{array}$ \\
\hline Middle & $\begin{array}{l}9.67^{*} \\
(0.06)\end{array}$ & $\begin{array}{l}-1.14 \\
(0.04)\end{array}$ & $\begin{array}{l}-1.01 \\
(0.01)\end{array}$ & $\begin{array}{l}-7.52 \\
(0.05)\end{array}$ \\
\hline Secondary & $\begin{array}{c}16.70^{* * * *} \\
(0.06)\end{array}$ & $\begin{array}{l}-0.82 \\
(0.03)\end{array}$ & $\begin{array}{l}-1.72 \\
(0.01)\end{array}$ & $\begin{array}{c}-14.20 * * * \\
(0.05)\end{array}$ \\
\hline Higher-secondary & $\begin{array}{c}17.40^{* * * *} \\
(0.06)\end{array}$ & $\begin{array}{c}-3.47 \\
(0.04)\end{array}$ & $\begin{array}{l}-1.65 \\
(0.01)\end{array}$ & $\begin{array}{c}-12.30^{* *} \\
(0.06)\end{array}$ \\
\hline Higher & $\begin{array}{c}24.10^{* * * *} \\
(0.07)\end{array}$ & $\begin{array}{l}-2.27 \\
(0.04)\end{array}$ & $\begin{array}{c}-2.58^{* *} \\
(0.01)\end{array}$ & $\begin{array}{c}-19.20 * * * \\
(0.06)\end{array}$ \\
\hline Mother autonomy & $\begin{array}{c}5.62 \\
(0.05)\end{array}$ & $\begin{array}{c}1.97 \\
(0.03)\end{array}$ & $\begin{array}{l}-0.38 \\
(0.01)\end{array}$ & $\begin{array}{c}-7.2 \\
(0.05)\end{array}$ \\
\hline \multicolumn{5}{|l|}{ Poverty score } \\
\hline Medium & $\begin{array}{c}-15.50^{* * *} \\
(0.02)\end{array}$ & $\begin{array}{c}-1.46 \\
(0.01)\end{array}$ & $\begin{array}{c}1.65^{* * *} \\
(0)\end{array}$ & $\begin{array}{c}15.30^{* * * *} \\
(0.02)\end{array}$ \\
\hline High & $\begin{array}{c}-25.10^{* * *} \\
(0.03)\end{array}$ & $\begin{array}{c}-2.71^{* *} \\
(0.01)\end{array}$ & $\begin{array}{c}2.41^{* * * *} \\
(0)\end{array}$ & $\begin{array}{c}25.40^{* * * *} \\
(0.02)\end{array}$ \\
\hline Gender of household head & $\begin{array}{c}-10 \\
(0.07)\end{array}$ & $\begin{array}{c}4.95 \\
(0.04)\end{array}$ & $\begin{array}{c}1.07 \\
(0.01)\end{array}$ & $\begin{array}{c}3.99 \\
(0.06)\end{array}$ \\
\hline Family size & $\begin{array}{c}0.37^{*} \\
(0)\end{array}$ & $\begin{array}{c}0.02 \\
(0)\end{array}$ & $\begin{array}{c}-0.10^{* * * *} \\
(0)\end{array}$ & $\begin{array}{c}-0.28^{*} \\
(0)\end{array}$ \\
\hline \multicolumn{5}{|l|}{ Gender of child } \\
\hline Male & $\begin{array}{c}9.29^{* * *} \\
(0.02\end{array}$ & $\begin{array}{c}3.91 * * * \\
(0.01)\end{array}$ & $\begin{array}{c}-0.55^{* * *} \\
(0)\end{array}$ & $\begin{array}{c}-12.60 * * * \\
(0.01)\end{array}$ \\
\hline Age & $\begin{array}{c}1.74^{* * *} \\
(0)\end{array}$ & $\begin{array}{c}0.63^{* * *} \\
(0)\end{array}$ & $\begin{array}{c}0.20^{* * *} \\
(0)\end{array}$ & $\begin{array}{c}-2.57^{* * * *} \\
(0)\end{array}$ \\
\hline \multicolumn{5}{|l|}{ Area } \\
\hline Rural & $\begin{array}{c}-6.84^{* * * *} \\
(0.02)\end{array}$ & $\begin{array}{c}5.87^{* * *} \\
(0.01)\end{array}$ & $\begin{array}{c}0.60^{* *} \\
(0)\end{array}$ & $\begin{array}{c}0.37 \\
(0.02)\end{array}$ \\
\hline \multicolumn{5}{|l|}{ Gender equity index } \\
\hline Medium & $\begin{array}{c}9.14^{* * *} \\
(0.02)\end{array}$ & $\begin{array}{l}-1.61 \\
(0.01)\end{array}$ & $\begin{array}{c}-0.69^{* * * *} \\
(0)\end{array}$ & $\begin{array}{c}-6.84^{* * * *} \\
(0.02)\end{array}$ \\
\hline High & $\begin{array}{c}9.00 * * * \\
(0.02)\end{array}$ & $\begin{array}{l}-2.23^{*} \\
(0.01)\end{array}$ & $\begin{array}{c}-0.60^{* *} \\
(0)\end{array}$ & $\begin{array}{c}-6.16^{* * *} \\
(0.02)\end{array}$ \\
\hline \multicolumn{5}{|l|}{ Division } \\
\hline Sukkur & $\begin{array}{c}4.17 \\
(0.03)\end{array}$ & $\begin{array}{c}5.97^{* * *} * \\
(0.01)\end{array}$ & $\begin{array}{c}0.33 \\
(0)\end{array}$ & $\begin{array}{c}-0.50^{* * *} \\
(0.02)\end{array}$ \\
\hline Hyderabad & $\begin{array}{l}-0.79 \\
(0.02)\end{array}$ & $\begin{array}{c}3.44^{* *} \\
(0.01)\end{array}$ & $\begin{array}{c}0.48 \\
(0)\end{array}$ & $\begin{array}{l}-3.13 \\
(0.02)\end{array}$ \\
\hline Mirpurkhas & $\begin{array}{c}-2.53 \\
(0.03)\end{array}$ & $\begin{array}{c}8.42^{* * *} \\
(0.02)\end{array}$ & $\begin{array}{c}0.79^{* *} \\
(0)\end{array}$ & $\begin{array}{c}-6.68^{* * *} \\
(0.02)\end{array}$ \\
\hline Karachi & $\begin{array}{c}13.50^{* * *} * \\
(0.03)\end{array}$ & $\begin{array}{c}-8.30^{* * *} * \\
(0.02)\end{array}$ & $\begin{array}{c}-0.90^{*} \\
(0)\end{array}$ & $\begin{array}{l}-4.33 \\
(0.03)\end{array}$ \\
\hline Observations & 3867 & 3867 & 3867 & 3867 \\
\hline
\end{tabular}

All values are in percentages and rounded off to two decimal place 
The result to an extent, does imply that higher autonomy within the household inclines women towards seeking more education and less work for their children. However, there is a richer understanding to this phenomenon; schooling and labour also increase with increasing levels of mother autonomy. This broadly implies that a woman who is more autonomous within the household is highly constrained externally (due to economic circumstances) and under such conditions both parents take decisions regarding the child.

\subsubsection{Hypothesis 3: Gender equity conditions play an important role in determining whether a child attends school, works or remains idle}

The results indicate that holding all other factors constant, an increase in the Gender Equity Index increases the probability of child schooling by 9 percent, decreases the probability of child work by 2 percent and similarly decreases idleness by 6 percent. Relatively empowered mothers choose schooling over rest of the three activities (student labour, labour and idleness) for their children. Higher gender equity reinforces mother empowerment and she chooses what is best with regard to her child's future. Jamal Haroon reports similar reports for Punjab, however for India, previous studies Kambhampati (2009) relate that an increase in gender equity increases child work.

\subsection{Impact of socioeconomic variables}

Other socioeconomic variables that are widely reported in literature have been used as control factors for this study. As these factors also significantly impact the decisions taken by parents for their children, we discuss them here briefly.

Parental education plays an important role in determining what activity the child pursues; educated parents are more likely to send their children to school. Males are 10 percent more likely to attend school as compared to females and males are 13 percent less likely to be idle than females. As age increases children are 2 percent more likely to attend school and 3 percent less likely to be idle.

Children residing in rural areas are 7 percent less likely to attend school, 6 percent more likely to attend school and work (and 0.4 percent more likely to be idle, however the coefficient is not significant).

\section{Conclusion}

The first focus of the study was on evaluating household poverty using a multidimensional approach and seeing its impact on a child's activities. We find that household poverty leads to decreased schooling and increased labor as well as idleness.

The second objective was to establish a relationship between mother autonomy within the household and how it influences a household's decision regarding child activity. The results indicate that increased autonomy of the mother within the household increases schooling and decreases idleness.

Lastly the study examined how the environment in which households live

Business Review: (2018) 13(1):37-51 
impacts the decision regarding child activities. It is revealed that an increase in gender equity increases the probability of a child attending school and decreases child labor as well as idleness.

Tackling poverty through conditional cash transfers could be used as an instrument to send children to school especially in regions where intense idleness is observed as well as those regions where there is low gender equality. However, due to data limitation this study does not look into the availability of schools in Sind and therefore this caveat should be considered before any policy making.

\section{References}

Acemoglu D, Robinson JA (2010) Why is africa poor? Economic history of developing regions 25(1):21-50

Afridi F (2010) Women's empowerment and the gender gap in schooling in india

Atteraya MS, Ebrahim NB, Gnawali S (2018) Determinants of child maltreatment in nepal: results from the 2014 nepal multiple indicator cluster survey (the 2014 nmics). Child abuse \& neglect 76:400-407

Awan MS, Waqas M, Aslam MA (2011) Why do parents make their children work? evidence from multiple indicator cluster survey

Azid T, Ejaz Ali Khan R (2010) Who are the children going to school in urban punjab (pakistan)? International Journal of Social Economics 37(6):442-465

Bacolod MP, Ranjan P (2008) Why children work, attend school, or stay idle: the roles of ability and household wealth. Economic Development and Cultural Change 56(4):791-828

Del Carpio XV (2008) Does Child Labor Always Decrease with Income? An evaluation in the context of a development program in Nicaragua. The World Bank

Duraisamy M, et al (2000) Child schooling and child work in india. Department of Humanities and Social Sciences, Indian Institute of Technology, Madras (Processed)

Eric E, Schady N (2009) Poverty alleviation and child labor. Tech. rep., mimeo, Department of Economics, Dartmouth College

Fatima A (2017) Child labour in pakistan: Addressing supply and demand side labour market dynamics. The Economic and Labour Relations Review 28(2):294-311

Haile G, Haile B (2012) Child labour and child schooling in rural ethiopia: nature and tradeoff. Education Economics 20(4):365-385

Hou X (2010) Wealth: Crucial but not sufficient-evidence from pakistan on economic growth, child labour and schooling. The Journal of Development Studies 46(3):439-465

Kambhampati US (2009) Child schooling and work decisions in india: The role of household and regional gender equity. Feminist Economics 15(4):77-112

Kazmi SMA (2015) How Does Socio-economic Factors Force Children Into Child Labour?: A Case Study of Sahiwal District, Punjab, Pakistan. Sustainable Development Policy Institute

Koissy KSA (2012) Child labor, schooling and household wealth in african rural area: luxury axiom or wealth paradox. Tech. rep., LISER

Krauss A (2013) Understanding Child Labor in Ghana Beyond PovertyThe Structure of the Economy, Social Norms, and No Returns to Rural Basic Education. The World Bank

Kravdal $\varnothing ~(2004)$ Child mortality in india: the community-level effect of education. Population studies 58(2):177-192

Lancaster G, Maitra P, Ray R (2006) Endogenous intra-household balance of power and its impact on expenditure patterns: Evidence from india. Economica 73(291):435-460

Padda IUH, Hameed A (2018) Estimating multidimensional poverty levels in rural pakistan: A contribution to sustainable development policies. Journal of Cleaner Production

Ray R, Basu K (2002) The collective model of the household and an unexpected implication for child labor: Hypothesis and an empirical test. The World Bank

Ray R, et al (2001) Child labour and child schooling in south asia: A cross country study of their determinants

Rosati FC, Rossi M (2003) Children's working hours and school enrollment: Evidence from pakistan and nicaragua. The World Bank Economic Review 17(2):283-295 


\section{Appendix}

This brief note is largely a verbatim of Technical Notes of UNDP Human Development Report (2011), while details of conceptual and other related issues in measurement of multidimensional poverty may be acquired from various $\mathrm{OPHI}^{5}$ working papers.

The Multidimensional Poverty Index (MPI) identifies multiple deprivations at the individual level in education, health and standard of living. Each person is assigned a deprivation score according to his or her household's deprivations in each of the 10 component indicators. The maximum score is 100 percent; with each dimension equally weighted (thus the maximum score in each dimension is 33.3 percent). The education and health dimensions have two indicators each, so each component is worth $5 / 3$ (or 16.7 percent). The standard of living dimension has six indicators, so each component is worth $5 / 9$ (or 5.6 percent).

\footnotetext{
5 http://ophi.org.uk/
} 